\title{
The differences between CRM and database marketing
}

Received (in revised form): 18th June, 2002

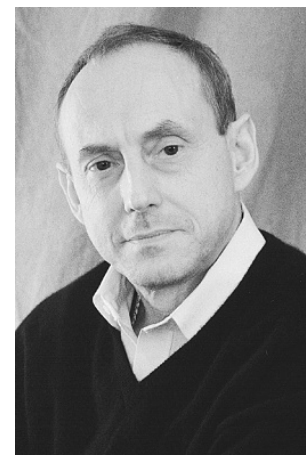

\section{Bob McKim}

is CEO of Software Solutions Group, a growing organisation that is dedicated to developing competitive CRM software applications designed for marketers. His career began at Gillette and he opened M/S Database Marketing in 1993 with his partner Evelyn Schlaphoff after gaining further experience as a traditional marketing director with Schick Electric and Bushnell Optical. He is an international lecturer, author, and writer, and is often asked to provide insight into database marketing initiatives and systems at conferences and for business and technical publications.

Abstract According to the Garmer Group, more than 50 per cent of CRM installations fail. Why? This paper reveals how industry leader's from BMW and Vivendi Universal to the Cranfield School of Management view CRM, and explains what marketers can realistically expect from CRM and Database Marketing. It will outline the similarities and differences of these two strategic disciplines, explore the reasons the companies that purchase them have problems with CRM, identify problems within the systems themselves, and explain what companies can do to solve these problems.

\section{INTRODUCTION}

The last few years have seen much activity in customer relationship marketing (CRM), and probably more written about the subject; yet it is only now that management is looking around and asking if there is any difference between CRM and database marketing. For the amount of money that is being poured into CRM, what exactly can be expected?

In terms of the costs, CRM appears to be the most expensive method to implement. Both disciplines have some very similar and overlapping characteristics and implementation costs, such as getting a 360-degree view of the customer and having all the data

Robert McKim SourceLink Software Solutions Group, 10866 Wilshire Blvd., Suite 650, Los Angeles, CA 90024, USA.

Tel: +1 (310) 208-2024; Fax: +1 (310) 208-5681; e-mail: rmckim@sourcelinkssg.com integrated into a common system.

Some companies spend between 8 per cent and 15 per cent of revenues on marketing expenses, depending on the industry and the competitive landscape. Marketing is a high leverage spending area. The Fortune 1000 companies' information technology (IT) departments generally spend between 5 and 7 per cent of their budgets on marketing-related support functions, according to Gartner.

There is no question that companies must adapt to the new technologies that come into the industry. Should they, however, be cautious and take the more tried and tested route, which makes them less adaptable in terms of being quick to market; or should they take the route of the high-cost newer technologies, which have not yet been proved to be successful, and implement them before the competition does?

\section{MAKING A CHOICE}

CRM relies more on new technology built for its own purposes, but has templates that fit for most marketing purposes. Database marketing uses existing technologies from established vendors (for example, Microsoft and Oracle) but requires extensive customisation. 
CRM technology promises to provide personalisation to every customer and prospect. Database marketing identifies unique segments in the database reacting to specific stimulus such as promotions.

Both are hindered if the data are not fully populated and there are inconsistencies in the data. Database marketing can be more successful and does not have to have every customer record populated with data.

The CRM promise is to strike up a relationship with the customer through affinities and personalised communication, thus making the customer more transactive. Database marketing anticipates customer behaviour over time and reacts to changes in the customer's behaviour. Database marketing relies more heavily on rule-based delivery of communications, whereas CRM waits for the customer to interact with the system.

CRM assumes that the customer wants a relationship with the company. Database marketing proactively delivers information or communication at key times when the customer is in the 'buying window'.

The metrics tend to be different as well. CRM talks and reports on a return on investment (ROI) basis. Database marketing reports activities on an ROI basis but talks and reports on customer lifetime value.

Moreover, CRM systems take up to a year to instal and get working, whereas database marketing systems will produce information and results in four to six months.

\section{PROBLEMS WITH CRM}

CRM has received negative publicity from early adapters who had the budget to spend on managing customer interactions inside the enterprise. Some of these criticisms have been in part due to the rapid market technologies not yet being ready for prime time. Another significant problem has been enthusiastic marketers who have bought the systems but without having the necessary knowledge and experienced assistance to help set them up.

The biggest problems the author has seen over the last few years with CRM or database marketing fall into three distinct areas:

- failure to identify the enterprise or company business problems accurately enough before buying the software and, therefore, being unprepared - lack of a common definition of CRM (database marketing has been around longer and does not seem to suffer from this problem). Vendors and clients seem to adapt the definition to suit what they sell or need from the corporation for budget approval

- lack of measurement by either the software or the purchaser of the technologies. Where have they accounted for the improved customer value, the trackable cost savings or the marginal lift between existing methods and the new CRM methods?

For the purposes of this paper, the author conducted some research among experts from all sides of the equation to give their opinion on the direction and value of CRM. The author considers that BMW has implemented a good CRM system, and has had the right idea of how long and how much it takes to get a CRM system implemented. Following is a definition of CRM from Kay Mandati, Relationship Manager for BMW North America:

'CRM is systematic, automatic, customised, targeted and relevant communications, initiated directly from data points, product relationships 
and other valuable consumer information, for the purpose of not only increasing loyalty and acquisition rates, but also ultimately to improve and manage consumer relationships in a more efficient and mutually beneficial manner. When executed correctly, top-level and first-class Consumer Relationship Marketing keeps communications relevant and engaging, while listening to our customers, facilitating a relationship on their terms, and delivering on our implicit commitments through the mediums they choose.'

When asked where she thought CRM was going, Kay Mandati replied:

'Unfortunately, too many companies think of CRM as a "quick pill" ... easy to take, with quick results. This perception leads many down the wrong path, ultimately to frustration. CRM is the complete opposite ... a long-term commitment, best when initiated in a well-defined scope and with clear objectives, and then slowly grown and expanded as successes and failures are realized. Companies that purchase high dollar/investment CRM systems and hope to cure cancer with them, often find themselves questioning, and possibly abandoning, their approach after seeing outright failure or no immediate ROI. This only perpetuates the general feeling that these systems are over priced expenditures of much needed resources that do little to affect day-to-day objectives.'

When asked where she considered CRM should be going, Kay's response was:

'Systems and technology purchases need to focus on the quick wins that CRM can achieve for an organization. CRM needs to be able to prove its worth by quickly focusing on a problem and then delivering results through implementation. A CRM system needs to be able to do this quickly, cheaply and efficiently. Once a few quick wins are realized, aligning an organization behind additional investments becomes easier to sell. Slowly, with CRM, you are able to address managing the consumer relationship, address different issues step by step rather than all at once.'
Joe Rapolla, CRM manager for Venvidi Universal Music Group, has eight business units focusing exclusively on uniting their multiple databases under one roof. It has taken over a year to build and define the business opportunities for their music group. His definition of CRM is thus:

'CRM means different things to different people ... and certainly applies differently to different industries. CRM is not a tool or a technology; it is a business practice that utilizes technology and requires organizational evolution. It's refining marketing strategies, offerings, and interactions based on the consistent consideration and application of intelligence about the consumer and marketplace. CRM means offering consumers products and services with an enlightened degree of confidence, because we know they have an interest in them. It's delivering messages in formats and channels that they prefer and that are the most efficient way to reach them. And it's getting smarter each time we communicate.'

Switching over from marketers to consultants and industry experts who have an interest in working with companies to ensure the smooth transition from mass marketing to targeted marketing, irrespective of what technologies are being used, the author turned to a long-term friend and colleague, author of many books on the subject, Arthur Hughes. This is his opinion on the subject:

'The Gartner Group reports that more than 50 per cent of CRM installations fail. Why? I think it is because those who use it assume that a warehouse plus CRM software will produce profits. They don't. What produces profits is a communications system that selects the right prospects and builds customer loyalty. CRM assumes you can predict customer behaviour using a warehouse. You can't.

Instead of building a multi-million dollar CRM warehouse, marketers would be advised 
to concentrate on building a database, and marketing to sectors of prospects and customers. That works, and costs only 10 per cent as much as a CRM warehouse.'

Doug Tanoury, a CRM historian and writer has this opinion:

'In 2000 and after, the visionary solution is now to regard each customer contact as a failure of process or product, and to address the root cause of those failures to design or engineer them away by process or product improvements. This solution of un-service is the future of at least 80 per cent of the CRM customer contact industry. The remaining 20 per cent are applications that bear revenue for companies and will function with highly skilled sales and knowledge workers empowered by powerful analytical and knowledge management technology to increase revenue and customer loyalty.

Companies that are now investing in traditional current CRM technology and initiatives are already behind the times and are investing in an area in the coming years that will be engineered away. So too are companies that are addressing customer needs by typical service and contact models of the last 20 years. Customer needs are being looked at in new and visionary ways from a process standpoint with service and product at its heart.'

\section{Don Himan, Vice President and Group} Leader for the Abilitec Product Group, Acxiom Corporation, has to face many challenges with mega-corporations as they try to implement a CRM system and tie all the various silos of data together, integrating them into a common unified data store and then implementing their CRM system. His view of the current state of CRM is as follows:

'Unfortunately, this technique has become too closely associated with the technology supporting it. Rather, we should look at the overall process of managing relationships with customers. That requires a technology platform, but more importantly, effective data and human intelligence. Each customer must be dealt with as a person who has needs and expectations about your service or product. Data helps us know what we 'need to know' to communicate effectively with our customer. CRM should be high touch, not just high tech'.

In terms of measurement, this is inevitably where the CRM system falls down. In most cases, the systems are not held accountable for the costs of implementation, the loss of productivity and the measurable difference between the newly implemented system and the 'old way' of doing it.

A Jupiter survey of Executives and IT managers revealed the following:

- 59 per cent said they had already deployed a data warehouse, from vendors such as Oracle and NCR, to store their customer data

- just 38 per cent said their customer data (eg profile and account information) resides in one, centralised repository

— only 30 per cent said they had deployed online analytical processing (OLAP) applications to analyse customer data

— just 29 per cent said they had deployed more sophisticated data mining applications, such as extraction transformation and loading (ETL) systems.

In one of its surveys Forrester found that, among 900 executives, 61 per cent will spend money in 2002 on hardware, software infrastructure or network bandwidth, while only 26 per cent will spend money on CRM, enterprise resource planning (ERP), procurement or supply chain systems. This is down from 58 per cent in 2001 , a very large reduction. 


\section{JUSTIFYING THE COST}

All of this still leaves the uncomfortable question about how to value and account for the costs of implementation, or changing from tried and tested systems to the newer systems which promise to integrate foreign data formats continuously into a centralised customer data store.

In a paper in a previous issue of this journal (Vol. 9, No. 3), Lynett Ryals, Director of the Executive MBA Programme at Cranfield School of Management, takes on the challenge. In the abstract she says:

\section{'Everybody in marketing is talking about customer relationship management (CRM), building on the relationship marketing idea that lifetime relationships with the customer are more effective and profitable. But how is CRM - the management of the customer — to be implemented?'}

Her approach is to value segments of the customer base like a portfolio of investments in which some customers will repay the additional investment. In her model from the perspective of CRM, analysing the risk of a customer or segment assists account managers to develop strategies to minimise the impact those riskier segments might have on the marketer. Her approach is to use a cash basis for evaluating what the risks are, versus the return less the implementation costs to come up with a method of evaluating each segment.
In the older school of database marketing, evaluation or metric focused on recency, frequency and monetary value (RFM) identifying profitable segments based upon either derived revenue or gross margin dollars.

Lifetime value emerged in the late 1990s and looked at the customer individually and their historic or prospective value to the corporation based upon net present value cost accounting, less the investment needed to turn that customer into a longer-term customer.

\section{CONCLUSION}

The troubling problem with CRM is that, like the definition, there is no accepted method of defining the value less the costs of implementation. Such a metric would need to consider the value of the customer in terms of the net present value, the cost of keeping the customer loyal, the cost per customer of the implementation of the CRM system (including loss of effective implementation over a given implementation period), the productivity gain of the system (if any), and the increase in customer value as a result of the implementation.

So, as CRM metamorphoses into yet another form with generally better definition and improved metrics, it will look more like the old database marketing using improved technology to implement the interactivity with contemporary Web-enabled software. 